\title{
HIMPUNAN $N$-LEMBUT KABUR HESITANT DAN APLIKASINYA DALAM PENGAMBILAN KEPUTUSAN
}

\author{
ATIA KHAIRUNI CAN, JENIZON \\ Program Studi S1 Matematika, \\ Fakultas Matematika dan Ilmu Pengetahuan Alam, Universitas Andalas, \\ Kampus UNAND Limau Manis Padang, Indonesia. \\ email : atiakhairunichan@gmail.com
}

Diterima 14 Oktober 2019 Direvisi 21 Oktober 2019 Dipublikasikan 3 Desember 2019

\begin{abstract}
Abstrak. Dalam kehidupan sehari-hari terdapat permasalahan yang mengandung unsur ketidakpastian atau ketidakjelasan. Zadeh pada tahun 1965 memperkenalkan teori Himpunan Kabur untuk mengatasi permasalahan tersebut dan teori ini berkembang menjadi beberapa teori lainnya. Pada tahun 1999, Molodstov memperkenalkan teori Himpunan Lembut yang kemudian berkembang menjadi Himpunan $N$-Lembut yang diperkenalkan oleh Fatia Fatimah. Teori Himpunan $N$-Lembut ini dapat dikombinasikan dengan beberapa teori yang berkembang dari Himpunan Kabur. Pada tulisan ini akan dibahas mengenai pengembangan dari Himpunan $N$-Lembut Kabur serta memperkenalkan konsep dari Himpunan $N$-Lembut Kabur Hesitant. Selanjutkan diberikan beberapa operasi yang berlaku pada Himpunan $N$-Lembut Kabur Hesitant, serta bagaimana pengaplikasiannya dalam pengambilan suatu keputusan.
\end{abstract}

Kata Kunci: Himpunan $N$-Lembut, Himpunan $N$-Lembut Kabur, Himpunan $N$-Lembut Kabur Hesitant

\section{Pendahuluan}

Himpunan tegas (crisp) adalah suatu himpunan dengan nilai keanggotaan sebesar satu untuk objek yang merupakan anggota himpunan dan nol untuk objek yang bukan anggota himpunan. Dalam kehidupan sehari-hari banyak permasalahan yang mengandung unsur ketidakpastian atau ketidakjelasan yang tidak dapat dinyatakan dengan himpunan tegas. Hal ini dikarenakan perubahan kecil terhadap suatu nilai pada himpunan tegas mangakibatkan perbedaan yang cukup signifikan.

Pada tahun 1965 Prof. Lotfi A. Zadeh [10] memperkenalkan suatu teori untuk mengatasi permasalahan tersebut yaitu teori Himpunan Kabur (Fuzzy Set). Teori Himpunan Kabur biasanya digunakan untuk mempermudah pengambilan keputusan pada permasalahan yang mengandung unsur ketidakpastian atau ketidakjelasan, dimana nilai keanggotaannya berada pada interval [0,1]. Pada tahun 1999, Molotstov [5] juga memperkenalkan Himpunan Lembut (Soft Set). Himpunan Lembut merupakan himpunan dari pasangan antara parameter atau atribut dengan objek-objek yang terkait. Dari Himpunan Kabur dan Himpunan Lembut, berkem- 
bang teori Himpunan Lembut Kabur (Fuzzy Soft Set), Himpunan Lembut Kabur Hesitant (Hesitant Fuzzy Soft Set) dan pengembangan lainnya.

Seiring berjalannya waktu, teori Himpunan Lembut berkembang menjadi teori Himpunan $N$-Lembut ( $N$-Soft $S e t$ ) yang diperkenalkan oleh Fatia Fatimah [3] pada tahun 2018. Teori ini membantu pengambilan keputusan untuk data multinary atau data berupa peringkat, rating atau kelas-kelas (grade). Pada tahun yang sama Akram [2] mengkombinasikan Himpunan $N$-Lembut dan Himpunan Kabur menjadi Himpunan $N$-Lembut Kabur (Fuzzy $N$-Soft Set). Sedangkan pada artikel ini akan dibahas mengenai Himpunan $N$-Lembut Kabur Hesitant (Hesitant Fuzzy N-Soft Set) dimana penilaian untuk setiap objek lebih dari satu nilai.

\section{Landasan Teori}

Definisi 2.1. [10] Misalkan $U$ adalah himpunan objek-objek. Suatu Himpunan Kabur (Fuzzy Set) F atas $U$ didefinisikan sebagai :

$$
F=\{(u, \mu(u)) \mid u \in U\}
$$

dimana $\mu: U \rightarrow[0,1]$ dan $\mu(u)$ merupakan nilai keanggotaan dari $u$.

Definisi 2.2. [7] Misalkan $U$ adalah himpunan objek-objek. Suatu Himpunan Kabur Hesitant (Hesitant Fuzzy Set) $H$ atas $U$ didefinisikan sebagai :

$$
H=\{(u, \sigma(u)) \mid u \in U\}
$$

dimana $\sigma: U \rightarrow \mathcal{P}^{*}[0,1]$ dengan $\mathcal{P}^{*}[0,1]$ adalah koleksi beberapa nilai dalam interval $[0,1]$.

Definisi 2.3. [3] Misalkan $U$ adalah himpunan objek-objek, E adalah suatu himpunan parameter atau atribut dan $A \subseteq E . R=\{0,1,2, \cdots, N-1\}$ adalah himpunan kelas (grade) dimana $N \in\{2,3, \cdots\}$. Suatu Himpunan $N$-Lembut ( $N$-Soft Set) $(F, A, N)$ atas $U$ didefinisikan sebagai :

$$
(F, A, N)=\{(a, F(a)) \mid a \in A\}
$$

dimana $F: A \rightarrow 2^{U \times R}$ sedemikian sehingga $F(a)=\left\{\left(u, r_{a u}\right) \mid u \in U, r_{a u} \in R\right\}$.

Definisi 2.4. [2] Misalkan $U$ adalah himpunan objek-objek dan E adalah himpunan parameter atau atribut, $A \subseteq E . K=(F, A, N)$ adalah suatu Himpunan $N$-Lembut atas $U$. Suatu Himpunan $\boldsymbol{N}$-Lembut Kabur (Fuzzy $N$-Soft Set) $(\mu, K)$ atas $U$ didefinisikan sebagai :

$$
(\mu, K)=\{(a, \mu(a)) \mid a \in A\}, \quad \text { dimana } \mu: A \rightarrow \bigcup_{a \in A} \mathcal{F}(F(a))
$$

$\mathcal{F}(F(a))$ adalah suatu Himpunan Kabur atas $F(a)$ dan $\left(u, r_{a u}\right) \in F(a)$. Dalam hal ini, $n_{a u}$ merupakan suatu nilai dalam interval $[0,1]$ yang merupakan nilai keanggotaan dari $u$ yang bersesuaian dengan parameter $a$. 


\section{Pembahasan}

Definisi 3.1. [1] Misalkan $U$ adalah himpunan objek-objek dan E adalah himpunan parameter atau atribut, $A \subseteq E$ dan $N \in\{2,3, \cdots\}$. Suatu Himpunan $N$-Lembut Kabur Hesitant (Hesitant Fuzzy N-Soft Set) $\left(\tilde{h}_{f}, A, N\right)$ atas $U$ didefinisikan sebagai :

$$
\left(\tilde{h}_{f}, A, N\right)=\left\{\left((u, a), \tilde{h}_{f}(u, a)\right) \mid a \in A, u \in U\right\},
$$

dimana $\tilde{h}_{f}: U \times A \rightarrow R \times \mathcal{P}^{*}([0,1])$, dengan $\mathcal{P}^{*}([0,1])$ adalah koleksi beberapa nilai dalam interval $[0,1]$. Didefinisikan $\tilde{h}_{f}(u, a)=\left(r_{a u}, m_{a u}\right)$ dengan $m_{a u} \in \mathcal{P}^{*}([0,1])$. Disini $m_{a u}$ merupakan himpunan nilai-nilai dalam interval [0,1] yang merupakan nilai keanggotaan dari u yang bersesuaian dengan parameter a.

Himpunan $N$-Lembut Kabur Hesitant $\left(\bar{h}_{f}, A, N\right)$ atas $U$ juga dapat dinya-takan dalam bentuk lain yaitu :

$$
\left(\bar{h}_{f}, A, N\right)=\left\{\left(a, \bar{h}_{f}(a)\right) \mid a \in A\right\}, \quad \operatorname{dimana} \bar{h}_{f}: A \longrightarrow \bigcup_{a \in A} \mathcal{H}(F(a)),
$$

$\mathcal{H}(F(a))$ adalah suatu Himpunan Kabur Hesitant atas $F(a)$.

Contoh 3.2. Misalkan Kementrian Komunikasi dan Informatika RI melaksanakan program beasiswa pelatihan IT kepada mahasiswa Strata-1. Untuk mendapatkan beasiswa tersebut terdapat beberapa kriteria penilaian. Misalkan $U=$ $\left\{u_{1}, u_{2}, u_{3}, u_{4}, u_{5}, u_{6}\right\}$ adalah himpunan orang-orang yang mendaftar untuk mendapatkan beasiswa dan $E=\left\{e_{1}, e_{2}, e_{3}, e_{4}\right\}$ adalah himpunan parameter yang akan dinilai. Misalkan parameter Jurusan " $e_{1}$ ", IPK (Indeks Prestasi Kumulatif) " $e_{2}$ ", Pengetahuan IT " $e_{3}$ " dan Tujuan " $e_{4} ", A \subseteq E$ dan $A=\left\{e_{1}, e_{2}, e_{3}, e_{4}\right\}$. Penilaian dilakukan secara online kemudian dilanjutkan tahap wawancara yang dilakukan oleh dua orang pewawancara dan diperoleh hasil penilaian seperti tabel berikut.

\begin{tabular}{|c|c|c|c|c|}
\hline $\mathrm{U} \backslash \mathrm{A}$ & Jurusan $\left(e_{1}\right)$ & $\operatorname{IPK}\left(e_{2}\right)$ & Pengetahuan $\operatorname{IT}\left(e_{3}\right)$ & Tujuan $\left(e_{4}\right)$ \\
\hline$u_{1}$ & $\left(\frac{4}{\{0.80,0.85\}}\right)$ & $\frac{4}{\{0.70,0.79\}}$ & $\frac{3}{\{0.70,0.73\}}$ & $\left.\frac{2}{\{0.60,0.75\}}\right)$ \\
\hline$u_{2}$ & $\left(\frac{4}{\{0.75 .0 .78\}}\right)$ & $\frac{3}{\{0.68,0.72\}}$ & $\frac{2}{\{0.60,0.65\}}$ & $\frac{3}{\{0.70,0.80\}}$ \\
\hline$u_{3}$ & $\left(\frac{3}{\{0.70 .0 .76\}}\right.$ & $\frac{2}{\{0.65,0.68\}}$ & $\frac{4}{\{0.70,0.77\}}$ & $\left(\frac{5}{\{0.80,0.88\}}\right.$ \\
\hline$u_{4}$ & $\left\{\frac{5}{\{0.85,0.87\}}\right.$ & $\frac{3}{\{0.70,0.80\}}$ & $\frac{2}{\{0.60 .0 .68\}}$ & $\left\{\frac{3}{\{0.70,0.76\}}\right.$ \\
\hline$u_{5}$ & $\left\{\frac{3}{\{0.740 .80\}}\right.$ & $\frac{3}{\{0.650 .70\}}$ & $\frac{5}{\{0.800 .85\}}$ & $\frac{5}{5090\}}$ \\
\hline$u_{6}$ & $\left(\frac{4}{\{0.77,0.80\}}\right)$ & $\frac{3}{\{0.75,0.76\}}$ & $\frac{3}{\{0.65,0.70\}}$ & $\left(\frac{4}{\{0.80,0.82\}}\right)$ \\
\hline
\end{tabular}

Tabel 1. Himpunan $N$-Lembut Kabur Hesitant $\left(\bar{h}_{f}, A, N\right)$

Definisi 3.3. [1] Misalkan $\left(\bar{h}_{f}, A, N\right)$ adalah suatu Himpunan N-Lembut Kabur Hesitant atas U. Suatu Komplemen Kabur Hesitant (Hesitant Fuzzy Complement) dari $\left(\bar{h}_{f}, A, N\right)$ didefinisikan sebagai :

$$
\begin{aligned}
\left(\bar{h}_{f}^{\prime}, A, N\right) & =\left\{\left(a, \bar{h}_{f}^{\prime}(a)\right) \mid a \in A\right\}=\left\{\left(a,\left\{\left(\frac{\left(u, r_{a u}\right)}{m_{a u}^{c}}\right) \mid u \in U\right\}\right) \mid a \in A\right\} \\
\text { dengan } m_{a u}^{c} & =\bigcup_{\lambda \in m_{a u}}\{1-\lambda\},\left(u, r_{a u}\right) \in F(a) .
\end{aligned}
$$


Definisi 3.4. [1] Misalkan $\left(\bar{h}_{f}, A, N\right)$ adalah suatu Himpunan N-Lembut Kabur Hesitant atas U. Suatu Komplemen Lemah Kabur Hesitant (Hesitant Fuzzy Weak Complement) dari $\left(\bar{h}_{f}, A, N\right)$ didefinisikan sebagai :

$$
\begin{aligned}
\left(\bar{h}_{f}^{c}, A, N\right) & =\left\{\left(a, \bar{h}_{f}^{c}(a)\right) \mid a \in A\right\}=\left\{\left(a,\left\{\left(\frac{\left(u, r_{a u}^{c}\right)}{m_{a u}^{c}}\right) \mid u \in U\right\}\right) \mid a \in A\right\} \\
\text { dengan } m_{a u}^{c} & =\bigcup_{\lambda \in m_{a u}}\{1-\lambda\}, r_{a u}^{c} \neq r_{a u},\left(u, r_{a u}\right) \in F(a)
\end{aligned}
$$

Definisi 3.5. [1] Misalkan $\left(\tilde{h}_{f}, A, N\right)$ adalah suatu Himpunan N-Lembut Kabur Hesitant atas U. Suatu Komplemen Kabur Hesitant Lemah Atas (Top Weak Hesitant Fuzzy Complement) $\left(\tilde{h}_{f}^{T}, A, N\right)$ dari $\left(\tilde{h}_{f}, A, N\right)$ didefinisikan sebagai :

$$
\begin{gathered}
\left(\tilde{h}_{f}^{T}, A, N\right)=\left\{\left((u, a), \tilde{h}_{f}^{T}(u, a)\right) \mid a \in A\right\}, \text { dengan } \\
\tilde{h}_{f}^{T}(u, a)= \begin{cases}\left\langle N-1, \bigcup_{\lambda \in m_{a u}}\{1-\lambda\}\right\rangle, \text { jika } r_{a u}<N-1 \\
\left\langle 0, \bigcup_{\lambda \in m_{a u}}\{1-\lambda\}\right\rangle & \text {,jika } r_{a u}=N-1 .\end{cases}
\end{gathered}
$$

Definisi 3.6. [1] Misalkan $\left(\tilde{h}_{f}, A, N\right)$ adalah suatu Himpunan N-Lembut Kabur Hesitant atas U. Suatu Komplemen Kabur Hesitant Lemah Bawah (Bottom Weak Hesitant Fuzzy Complement) $\left(\tilde{h}_{f}^{B}, A, N\right)$ dari $\left(\tilde{h}_{f}, A, N\right)$ didefinisikan sebagai:

$$
\begin{aligned}
& \left(\tilde{h}_{f}^{B}, A, N\right)=\left\{\left((u, a), \tilde{h}_{f}^{B}(u, a)\right) \mid a \in A\right\}, \text { dengan }
\end{aligned}
$$

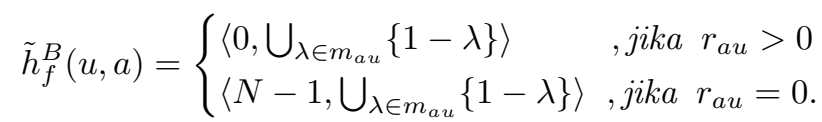

Definisi 3.7. [1] Misalkan $\left(\tilde{h}_{f_{1}}, A, N_{1}\right)$ dan $\left(\tilde{h}_{f_{2}}, B, N_{2}\right)$ adalah dua Himpunan $N$ Lembut Kabur Hesitant atas U. Suatu irisan terbatas (restricted intersection), $\cap_{\Re}\left(\tilde{h}_{f}, C, N\right)$ dari keduanya dinyatakan sebagai :

$$
\left(\tilde{h}_{f}, C, N\right)=\left(\tilde{h}_{f_{1}}, A, N_{1}\right) \cap_{\Re}\left(\tilde{h}_{f_{2}}, B, N_{2}\right)=\left(\tilde{h}_{f}, A \cap B, \min \left\{N_{1}, N_{2}\right\}\right)
$$

dimana untuk setiap $c \in A \cap B$ dan $u \in U$, berlaku $\tilde{h}_{f}(u, c)=\left(r_{c u}, m_{c u}\right)$ jika dan hanya jika $r_{c u}=\min \left\{r_{a u}, r_{b u}\right\}$ dan $m_{c u}=\left\{\lambda \in m_{a u} \cup m_{b u} \mid \lambda \leqslant\right.$ $\left.\min \left\{m_{a u}{ }^{+}, m_{b u}{ }^{+}\right\}\right\}$dengan $\left(r_{a u}, m_{a u}\right)=\tilde{h}_{f_{1}}(u, a),\left(r_{b u}, m_{b u}\right)=\tilde{h}_{f_{2}}(u, b)$ dan $a \in A, b \in B$ dimana $m_{a u}{ }^{+}=\operatorname{maks}\left\{m_{a u}\right\} \operatorname{dan} m_{b u}{ }^{+}=\operatorname{maks}\left\{m_{b u}\right\}$.

Definisi 3.8. [1] Misalkan $\left(\tilde{h}_{f_{1}}, A, N_{1}\right)$ dan $\left(\tilde{h}_{f_{2}}, B, N_{2}\right)$ adalah dua Himpunan $N$ Lembut Kabur Hesitant atas U. Suatu irisan diperumum (extended intersection), $\cap_{\mathcal{E}}\left(\tilde{h}_{f}, C, N\right)$ dari keduanya dinyatakan sebagai :

$$
\left(\tilde{h}_{f}, C, N\right)=\left(\tilde{h}_{f_{1}}, A, N_{1}\right) \cap_{\mathcal{E}}\left(\tilde{h}_{f_{2}}, B, N_{2}\right)=\left(\tilde{h}_{f}, A \cup B, \operatorname{maks}\left\{N_{1}, N_{2}\right\}\right),
$$

dimana untuk setiap $c \in A \cup B$ dan $u \in U$, berlaku $\tilde{h}_{f}(u, c)=\left(r_{c u}, m_{c u}\right)$ jika dan hanya jika : 


$$
\tilde{h}_{f}(u, c)=\left\{\begin{array}{l}
\tilde{h}_{f_{1}}(u, a), j i k a c \in A-B \\
\tilde{h}_{f_{2}}(u, b), j i k a c \in B-A \\
\left(r_{c u}, m_{c u}\right), j i k a c \in A \cap B, \text { dengan } r_{c u}=\min \left\{r_{a u}, r_{b u}\right\} \text { dan } \\
\quad m_{c u}=\left\{\lambda \in m_{a u} \cup m_{b u} \mid \lambda \leqslant \min \left\{m_{a u}{ }^{+}, m_{b u}+\right\}\right\} .
\end{array}\right.
$$

Definisi 3.9. [1] Misalkan $\left(\tilde{h}_{f_{1}}, A, N_{1}\right)$ dan $\left(\tilde{h}_{f_{2}}, B, N_{2}\right)$ adalah dua Himpunan $N$ Lembut Kabur Hesitant atas U. Suatu gabungan terbatas (restricted union), $\cup_{\Re}$ $\left(\tilde{h}_{f}, C, N\right)$ dari keduanya dinyatakan sebagai :

$$
\left(\tilde{h}_{f}, C, N\right)=\left(\tilde{h}_{f_{1}}, A, N_{1}\right) \cup_{\Re}\left(\tilde{h}_{f_{2}}, B, N_{2}\right)=\left(\tilde{h}_{f}, A \cap B, \operatorname{maks}\left\{N_{1}, N_{2}\right\}\right)
$$

dimana untuk setiap $c \in A \cap B$ dan $u \in U$, berlaku $\left(r_{c u}, m_{c u}\right) \in \tilde{h}_{f}(u, c)$ jika dan hanya jika $r_{c u}=\operatorname{maks}\left\{r_{a u}, r_{b u}\right\}$ dan $m_{c u}=\left\{\lambda \in m_{a u} \cup m_{b u} \mid \lambda \geqslant\right.$ $\left.\operatorname{maks}\left\{m_{a u}{ }^{-}, m_{b u}{ }^{-}\right\}\right\}$. Dalam hal ini, $\left(r_{a u}, m_{a u}\right)=\tilde{h}_{f_{1}}(u, a),\left(r_{b u}, m_{b u}\right)=\tilde{h}_{f_{2}}(u, b)$, $a \in A, b \in B, m_{a u}{ }^{-}=\min \left\{m_{a u}\right\}$ dan $m_{b u}{ }^{-}=\min \left\{m_{b u}\right\}$.

Definisi 3.10. [1] Misalkan $\left(\tilde{h}_{f_{1}}, A, N_{1}\right)$ dan $\left(\tilde{h}_{f_{2}}, B, N_{2}\right)$ adalah dua Himpunan $N$ Lembut Kabur Hesitant atas U. Suatu gabungan diperumum (extended union), $\cup_{\mathcal{E}}\left(\tilde{h}_{f}, C, N\right)$ dari keduanya dinyatakan sebagai :

$$
\left(\tilde{h}_{f}, C, N\right)=\left(\tilde{h}_{f_{1}}, A, N_{1}\right) \cup_{\mathcal{E}}\left(\tilde{h}_{f_{2}}, B, N_{2}\right)=\left(\tilde{h}_{f}, A \cup B, \operatorname{maks}\left\{N_{1}, N_{2}\right\}\right)
$$

dimana untuk setiap $c \in A \cup B$ dan $u \in U$, berlaku $\tilde{h}_{f}(u, c)=\left(r_{c u}, m_{c u}\right)$ jika dan hanya jika :

$$
\tilde{h}_{f}(u, c)=\left\{\begin{aligned}
\tilde{h}_{f_{1}}(u, a), \text {,jika } c \in A-B \\
\tilde{h}_{f_{2}}(u, b), \text { jika } c \in B-A \\
\left(r_{c u}, m_{c u}\right), j i k a \quad c \in A \cap B, \text { dengan } r_{c u}=\operatorname{maks}\left\{r_{a u}, r_{b u}\right\} \text { dan } \\
m_{c u}=\left\{\lambda \in m_{a u} \cup m_{b u} \mid \lambda \geqslant \operatorname{maks}\left\{m_{a u}{ }^{-}, m_{b u}{ }^{-}\right\}\right\} .
\end{aligned}\right.
$$

\section{Aplikasi}

Kwang dan Yoon pada tahun 1981 [4] memperkenalkan suatu algoritma dalam mengambil keputusan dengan memperhatikan parameter atau atribut yang disebut TOPSIS (Technique for Order Preference by Similarity to Ideal Solution). TOPSIS digunakan berdasarkan konsep bahwa pemilihan objek-objek harus mempunyai jarak terdekat dengan suatu himpunan yang disebut dengan solusi ideal positif dan jarak terjauh dengan solusi ideal negatif. Maka berdasarkan konsep tersebut, diberikan suatu algoritma berikut untuk pengambilan keputusan dengan menggunakan konsep Himpunan $N$-Lembut Kabur Hesitant.

(1) Diketahui matriks $D$ berdasarkan algoritma pertama. Akan ditentukan solusi ideal positif $\left(B^{+}\right)$dan solusi ideal negatif $\left(B^{-}\right)$.

$$
\begin{aligned}
& B^{+}=\left\{\left(r_{j}{ }^{+},\left\{\left(\lambda_{j}{ }^{1}\right)^{+},\left(\lambda_{j}{ }^{2}\right)^{+}, \ldots,\left(\lambda_{j}{ }^{k}\right)^{+}\right\}\right) j=1,2, \ldots, q\right\} \\
& B^{-}=\left\{\left(r_{j}{ }^{-},\left\{\left(\lambda_{j}{ }^{1}\right)^{-},\left(\lambda_{j}{ }^{2}\right)^{-}, \ldots,\left(\lambda_{j}{ }^{k}\right)^{-}\right\}\right) j=1,2, \ldots, q\right\}
\end{aligned}
$$




$$
\begin{aligned}
& \text { dimana, } r_{j}{ }^{+}=\max _{i}\left(r_{i j}\right) \quad r_{j}{ }^{-}=\min _{i}\left(r_{i j}\right) \\
& \left(\lambda_{j}{ }^{1}\right)^{+}=\max _{i}\left(\lambda_{i j}{ }^{1}\right) \quad\left(\lambda_{j}{ }^{1}\right)^{-}=\min _{i}\left(\lambda_{i j}{ }^{1}\right) \\
& \left(\lambda_{j}^{2}\right)^{+}=\max _{i}\left(\lambda_{i j}{ }^{2}\right) \quad\left(\lambda_{j}^{2}\right)^{-}=\min _{i}\left(\lambda_{i j}{ }^{2}\right) \\
& \left(\lambda_{j}{ }^{k}\right)^{+}=\max _{i}\left(\lambda_{i j}{ }^{k}\right) \quad\left(\lambda_{j}{ }^{k}\right)^{-}=\min _{i}\left(\lambda_{i j}{ }^{k}\right)
\end{aligned}
$$

(2) Hitung ukuran pemisahan $S^{+}$dan $S^{-}$dengan menambahkan bobot $\left(\sigma_{j}\right)$ untuk masing-masing parameter.

$$
\begin{array}{rlrl}
S_{i}^{+} & =\left(R_{i}^{+}, M_{i}^{+}\right), & S_{i}^{-} & =\left(R_{j}^{-}, M_{j}^{-}\right), \quad i=1,2, \ldots, p \\
R_{i}^{+} & =\sum_{j=1}^{q} \sigma_{j}\left|r_{i j}-\left(r_{j}\right)^{+}\right|, & R_{i}^{-} & =\sum_{j=1}^{q} \sigma_{j}\left|r_{i j}-\left(r_{j}\right)^{-}\right| \\
M_{i}^{+} & =\sum_{j=1}^{q} \sigma_{j} \sqrt{\frac{1}{k} \sum_{l=1}^{k}\left|\lambda_{i j}^{l}-\left(\lambda_{j}{ }^{l}\right)^{+}\right|^{2}}, & M_{i}^{-}=\sum_{j=1}^{q} \sigma_{j} \sqrt{\frac{1}{k} \sum_{l=1}^{k}\left|\lambda_{i j}{ }^{l}-\left(\lambda_{j}{ }^{l}\right)^{-}\right|^{2} .}
\end{array}
$$

(3) Hitung kedekatan relatif ke solusi ideal $(C, c)=\left[C_{i}, c_{i}\right]$.

$$
\begin{aligned}
\left(C_{i}, c_{i}\right)= & \left(\frac{R_{i}^{-}}{{R_{i}{ }^{+}+R_{i}^{-}}^{-}}, \frac{M_{i}^{-}}{M_{i}^{+}+M_{i}^{-}}\right), \quad 0<C_{i}<1,0<c_{i}<1, \\
& i=1,2, \ldots, p .
\end{aligned}
$$

(4) Bentuk matriks $E=\left[E_{i}\right]$ dan urutkan hasil yang didapatkan.

$$
E_{i}=\frac{C_{i}+c_{i}}{2}, i=1,2, \ldots, p .
$$

Contoh 4.1. Suatu universitas akan menyelenggarakan pemilihan rektor. Pemilihan dilakukan oleh seluruh anggota senat dan juga Kemenristekdikti. Penilaian pertama dilakukan oleh Kemenristekdikti dengan menggunakan sistem voting dan penilaian kedua dilakukan oleh anggota senat. Terdapat beberapa kriteria penilaian (parameter) dan masing-masing kriteria dibagi lagi menjadi beberapa indikator penilaian, sehingga diperoleh data seperti berikut.

Data Hasil Penilaian Calon-calon Rektor

\begin{tabular}{|c|c|c|c|c|c|}
\hline$U \backslash A$ & $e_{1}$ & $e_{2}$ & $e_{3}$ & $e_{4}$ & $e_{5}$ \\
\hline$u_{1}$ & $\left(\frac{2}{\{0.6,0.65,0.7\}}, 0.185\right)$ & $\left(\frac{2}{\{0.55,0.6,0.65,0.67\}}, 0.23\right)$ & $\left(\frac{2}{\{0.5,0.53,0.6,0.62,0.65\}}, 0.25\right)$ & $\left(\frac{3}{\{0.7,0.75,0.77\}}, 0.185\right)$ & $\left(\frac{2}{\{0.6,0.64,0.7\}}, 0.15\right)$ \\
$u_{2}$ & $\left(\frac{2}{\{0.65,0.68,0.7\}}, 0.185\right)$ & $\left(\frac{1}{\{0.5,0.57,0.6,0.68\}}, 0.23\right)$ & $\left(\frac{3}{\{0.6,0.64,0.7,0.72,0.75\}}, 0.25\right)$ & $\left(\frac{2}{\{0.65,0.7,0.78\}}, 0.185\right)$ & $\left(\frac{3}{\{0.78,0.8,0.83\}}, 0.15\right)$ \\
$u_{3}$ & $\left(\frac{3}{\{0.7,0.75,0.77\}}, 0.185\right)$ & $\left(\frac{2}{\{0.6,0.67,0.7,0.73\}}, 0.23\right)$ & $\left(\frac{2}{\{0.47,0.5,0.55,0.65,0.7\}}, 0.25\right)$ & $\left(\frac{1}{\{0.55,0.65,0.72\}}, 0.185\right)$ & $\left(\frac{3}{\{0.75,0.8,0.82\}}, 0.15\right)$ \\
$u_{4}$ & $\left(\frac{2}{\{0.7,0.75,0.78\}}, 0.185\right)$ & $\left(\frac{2}{\{0.62,0.7,0.73,0.77\}}, 0.23\right)$ & $\left(\frac{3}{\{0.67,0.7,0.74,0.78,0.8\}}, 0.25\right)$ & $\left(\frac{1}{\{0.58,0.62,0.7\}}, 0.185\right)$ & $\left(\frac{3}{\{0.7,0.8,0.85\}}, 0.15\right)$ \\
\hline
\end{tabular}


Untuk menentukan calon Rektor yang terbaik, digunakan konsep Himpunan $N$-Lembut Kabur Hesitant dengan langkah-langkah sebagai berikut.

(1) Misalkan $U=\left\{u_{1}, u_{2}, u_{3}, u_{4}\right\}$ merupakan himpunan calon-calon rektor dan $A=\left\{e_{1}, e_{2}, e_{3}, e_{4}, e_{5}\right\}$ merupakan beberapa kriteria penilaian yakni, Integritas " $e_{1}$ ", Komitmen " $e_{2}$ ", Kepemimpinan " $e_{3}$ ", Manajerial dan Administrator " $e_{4}$ " dan Jiwa Interprenuer " $e_{5}$ ". Misalkan $N=4$ sehingga diperoleh $R=\{0,1,2,3\}$ adalah himpunan kelas (grade).

(2) Dari data dibentuk matriks $D$ untuk mempermudah pengambilan keputusan.

$$
D=\left[\begin{array}{ccccc}
\left(\frac{2}{\{0.6,0.65,0.7\}}, 0.185\right) & \left(\frac{2}{\{0.55,0.6,0.65,0.67\}}, 0.23\right) & \left(\frac{2}{\{0.5,0.53,0.6,0.62,0.65\}}, 0.25\right) & \left(\frac{3}{\{0.7,0.75,0.77\}}, 0.185\right) & \left(\frac{2}{\{0.6,0.64,0.7\}}, 0.15\right) \\
\left(\frac{2}{\{0.65,0.68,0.7\}}, 0.185\right) & \left(\frac{1}{\{0.5,0.57,0.6,0.68\}}, 0.23\right) & \left(\frac{3}{\{0.6,0.64,0.7,0.72,0.75\}}, 0.25\right) & \left(\frac{2}{\{0.65,0.7,0.78\}}, 0.185\right) & \left(\frac{3}{\{0.78,0.8,0.83\}}, 0.15\right) \\
\left(\frac{3}{\{0.7,0.75,0.77\}}, 0.185\right) & \left(\frac{2}{\{0.6,0.67,0.7,0.73\}}, 0.23\right) & \left(\frac{2}{\{0.47,0.5,0.55,0.65,0.7\}}, 0.25\right) & \left(\frac{1}{\{0.55,0.65,0.72\}}, 0.185\right) & \left(\frac{3}{\{0.75,0.8,0.82\}}, 0.15\right) \\
\left(\frac{2}{\{0.7,0.75,0.78\}}, 0.185\right) & \left(\frac{2}{\{0.62,0.7,0.73,0.77\}}, 0.23\right) & \left(\frac{3}{\{0.67,0.7,0.74,0.78,0.25\}}, 0.25\right) & \left(\frac{1}{\{0.58,0.62,0.7\}}, 0.185\right) & \left(\frac{3}{\{0.7,0.8,0.85\}}, 0.15\right)
\end{array}\right]
$$

(3) Tentukan solusi ideal positif $\left(B^{+}\right)$dan solusi ideal negatif $\left(B^{-}\right)$.

$$
\begin{aligned}
& \begin{aligned}
B^{+}= & {\left[\left(\frac{3}{0.7,0.75,0.78}\right)\left(\frac{2}{0.62,0.7,0.73,0.77}\right)\left(\frac{3}{0.67,0.7,0.74,0.78,0.8}\right)\right.} \\
& \left.\left(\frac{3}{0.7,0.75,0.78}\right) \quad\left(\frac{3}{0.78,0.8,0.85}\right)\right]
\end{aligned} \\
& \begin{aligned}
B^{-}= & {\left[\left(\frac{2}{0.6,0.65,0.7}\right)\left(\frac{1}{0.5,0.57,0.6,0.67}\right)\left(\frac{2}{0.47,0.5,0.55,0.62,0.65}\right)\right.} \\
& \left.\left(\frac{1}{0.55,0.62,0.7}\right) \quad\left(\frac{2}{0.6,0.64,0.7}\right)\right]
\end{aligned}
\end{aligned}
$$

(4) Hitung ukuran pemisahan dari data, yaitu $S^{+}=\left[\left(R_{i}^{+}, M_{i}^{+}\right)\right]$dan $S^{-}=$ $\left[\left(R_{i}^{-}, M_{i}^{-}\right)\right]$.

$$
S^{+}=\left[\begin{array}{l}
(.5850, .0960) \\
(.6000, .0633) \\
(.6200, .0718) \\
(.3700, .0276)
\end{array}\right] \quad, \quad S^{-}=\left[\begin{array}{l}
(.5900, .0400) \\
(.4850, .0712) \\
(.5650, .0503) \\
(.6300, .0917)
\end{array}\right]
$$

(5) Hitung kedekatan relatif ke solusi ideal $(C, c)=\left[\left(C_{i}, c_{i}\right)\right]$.

$$
(C, c)=\left[\begin{array}{l}
(.5021, .2941) \\
(.4470, .5294) \\
(.4768, .4120) \\
(.6300, .7687)
\end{array}\right]
$$

(6) Bentuk matriks $E=\left[E_{i}\right]$ dan urutkan hasil yang didapatkan, sehingga diperoleh hasil keputusan.

$$
E=\left[\begin{array}{l}
(.3981) \\
(.4882) \\
(.4444) \\
(.6994)
\end{array}\right] \quad, \quad E_{1}<E_{3}<E_{2}<E_{4}
$$


(7) Kesimpulan : diperoleh urutan calon rektor dari yang terbaik adalah $U_{4}, U_{2}, U_{3}$ dan $U_{1}$.

\section{Kesimpulan}

Himpunan $N$-Lembut Kabur Hesitant merupakan perumuman dari Himpunan $N$ Lembut Kabur dan Himpunan $N$-Lembut. Himpunan $N$-Lembut Kabur He-sitant dengan nilai keanggotaan terdiri dari satu nilai maka menjadi Himpunan $N$-Lembut Kabur. Sedangkan Himpunan $N$-Lembut Kabur Hesitant dengan nilai keanggotaan sama dengan nol untuk setiap objeknya maka menjadi Himpunan $N$-Lembut. Pada Himpunan $N$-Lembut Kabur Hesitant berlaku operasi irisan dan gabu-ngan yang terdiri dari irisan terbatas, irisan diperumum, gabungan terbatas dan gabungan diperumum. Pengambilan keputusan pada Himpunan $N$-Lembut Kabur tidak mempertimbangkan keraguan dalam pemberian nilai atau tidak dapat digunakan untuk data yang memiliki penilaian lebih dari satu nilai untuk masing-masing objeknya. Sedangkan dalam kehidupan sehari-hari penilaian terhadap suatu objek bisa lebih dari satu nilai. Untuk mengatasi permasalahan tersebut dibentuklah Himpunan $N$ Lembut Kabur Hesitant dimana pengambilan kepusan menggunakan teori Himpunan $N$-Lembut Kabur Hesitant memberikan hasil yang lebih baik terhadap permasalahan tersebut.

\section{Daftar Pustaka}

[1] Akram, M. dan Arooj A. 2019. Hesitant Fuzzy N-Soft Sets : A Novel Model with Applications in Decision Making. Intelligent and Fuzzy Systems. 36(6) : $6113-6127$

[2] Akram, M. dan Arooj A. 2018. Fuzzy N-Soft Sets : A Novel Model with Applications in Decision Making. Intelligent and Fuzzy Systems. 35(4): 4757 - 4771

[3] Fatimah F. dan Dedi R. 2018. N-Soft Sets and Their Decision Making Algorithms, Soft Computing. 22(12): 3829 - 3842

[4] Kwang, C. L. dan Kwangsun Y. 1981. Multiple Attribute Decision Making Methods and Applications. Springer Verlag, Berlin Heidelberg New York

[5] Molodtsov, D. 1999. Soft Set Theory First Result. Computers and Mathematics with Applications. 37(4-5): $19-31$

[6] Roy, A. R. dan P. K. Maji, 2007. A Fuzzy Soft Set Theoretic Approach to Decition Making Problems. Computational and Applied Mathematics. 203(2): $412-418$

[7] Torra, V. 2010. Hesitant Fuzzy Set. Intelligent Systems 25(6): 529 - 539

[8] Wang, F. dan Xihua L. 2014. Hesitant Fuzzy Soft Set and Its Applications in Multicriteria Decision Making. Applied Mathematics. Vol. 2014, Article ID 643785

[9] Xiao, Z. dan Xianglei Y. 2012. A New Evaluation Method Based on D-S Generalized Fuzzy Soft Sets and Its Aplication in Medical Diagnosis Problem. Applied Mathematical Modelling. 36(10): 4592 - 4604

[10] Zadeh, L. A. 1965. Fuzzy Sets. Information and Control. 8(3): $338-353$ 